IJMS 19 (1), 37-51 (2012)

\title{
THE EFFECTS OF INTEREST RATES VOLATILITY ON STOCK MARKET RETURNS IN MALAYSIA AND SINGAPORE
}

\author{
KAREN TAN \\ MOHAMED HISHAM YAHYA \\ AMIN NORDIN BANY ARIFFIN \\ Faculty of Economics and Management \\ Universiti Putra Malaysia
}

\begin{abstract}
This research examines the effects of interest rates volatility on stock market returns in Malaysia and Singapore. The data used are market returns on the FBM Kuala Lumpur Composite Index (FBM KLCI) and 3-months deposit yields in Malaysia over the period of September 1999 to December 2010. For the Singaporean market, the monthly data of market returns on the Straits Times Index (STI) and 3-months deposit yields in Singapore during the same period are used. Two separate GARCH $(1,1)$ models are applied for Malaysia and Singapore. Results suggest that interest rate volatility in each country has a strong positive relationship with its respective stock market volatility. The results also show that the volatility of interest rates has a negative relationship with the stock market return but the relationship is insignificant.
\end{abstract}

Keywords: Interest rates, stock market, GARCH, Malaysia, Singapore, FBM KLCI, STI.

\section{Introduction}

Interest rate risk is one of the significant financial and economic factors that have an effect on the common stock value. Interest rate reflects the price of money and has influence on other variables in the capital and money market. When interest rates increase, they have a negative effect on the value of financial assets by increasing their required rate of return. For example, the increase of interest rates might direct investors to change the structure of their investments from capital markets to fixed income securities markets. In contrast, the decline of interest rates leads to the rise in the present value of the future dividend (Hashemzadeh \& Taylor, 1988). 
A financial market is a market place where movements of funds from savers to investors occur. A stock market is the subset of the financial market which plays an important role in the growth and development of economy. In fact, the changes in the demand of equities in the stock market closely affect the stock market return and volatility. Stock return volatility refers to the variation in the change of stock price during a period of time. The higher the variation, the higher the risk of a particular stock is. Generally, policy makers are more interested in looking for the determinants of stock market volatility, while market practitioners are keener towards the effect of stock market volatility on hedging options and more exotic derivatives. Stock volatility may weaken the smooth functioning of the financial system and adversely affect the economic performance. The volatility of the stock market has been proven to have a number of negative impacts in economic performance. It affects the economy through its effect on consumer spending (Poterba, 2000), business investment (Zuliu, 1995) and economic growth (Levine \& Zervos, 1996).

Prior researches have investigated the determinants of stock market return for the last several years. There are a number of factors that influence the general movement of stock prices in the market. The connection between macroeconomic variables and the movement of stock prices for developed countries have well been documented in several literature (Fama, 1981; Kaneko \& Lee, 1995; Maysami \& Koh, 2000; Chen, 2003). Interest rate is suggested as one of the macroeconomic variables that could affect stock market volatility (Ramin \& Lee, 2004). Studies on the relationship between the behaviours of the stock market and macroeconomic factors are numerous in the literature. These studies, however, have concentrated on the developed markets of the United States, Europe and Japan. Among others, Fama (1981, 1990, 1991) documented the relationship between stock market returns and fundamental economic activities in the United States. Chen (1991) and Fama (1991) model the relationship between asset prices and real economic activities in terms of production rates, interest rates, inflation and so on and so forth. In the Malaysian and Singaporean context, Ibrahim (2000), Ibrahim and Aziz (2003), Ramin, Lee and Mohamad (2004) and Janor (2005) investigate the dynamic interactions between the stock market and economic activities.

Among the macroeconomic factors, interest rate is suggested as one of the factors that might affect stock return and volatility. A reduction in interest rates would reduce the cost of capital for calculating the 
price of financial assets. Tight controls on lending may have limited borrowing to finance the acquisition of assets, while relaxation of controls may increase demand for assets including equities. An effective relaxation of controls on bank lending is likely to raise asset prices and could result in bankers and others misreading price signals and in over-lending by banks and over-trading by their customers. Increased competition among lenders could lead to customers gearing up their operations and taking greater risks, and hence lead to more defaults (Kaufman, 1986; Davis, 1990).

Even though many studies have documented the strong relationship amongst the equity market and macroeconomic variables especially in western countries, there is still a need to pursue the issue in relation to the Malaysian and Singapore markets. This is due to the fact that the structure of the Malaysian (emerging market) and Singapore (developed market) stock markets are significantly different in terms of market capitalization and liquidity. From the perspective of the monetary policy in Malaysia and Singapore, the change in interest rate would indeed affect the demand of equity in the financial market. Respective central banks will adjust the interest rate accordingly based on the condition of the economy. When the inflation is high and economy is overheating, the central bank will actually tighten the monetary policy by withdrawing funds from the banking system and increasing the interest rates. The volatility of the stock market has been proven to affect the overall economy, therefore, the determinants of the stock market returns and volatility have to be examined in order to consolidate the future stock market returns forecasting. Interest rate is one of the stock markets return determinants (Ramin \& Lee, 2004), however, only a few studies have been conducted in examining the influence of interest rate volatility towards stock market returns in Malaysia and Singapore, for example, Cheong (2008) and Islam (2003). While previous studies by Ramin et al. (2004) and Aisyah, Noor and Fauziah (2009) put emphasis on studying the determinants of the stock market, this paper studies the effect of interest rate volatility on the stock market.

The objective of this research is to contribute to the existing literature on the relationship between interest rates and stock returns and volatility in Malaysia (emerging market) and Singapore (developed market) stock markets. By examining the predictive power of the interest rate volatility on stock market performance, investors will be able to make better security investment decision by monitoring the changes of interest rates. This research will focus on examining 
the predictive role of interest rate volatility towards stock market returns and volatility. This research is important in consolidating the predictive power of future stock market returns in Malaysia by looking into interest rate volatility. The result from this research would be useful in the process of decision-making especially for investors, corporations, and regulators. It would also help to widen the horizon of investors when they come to equity portfolio management decisions.

\section{Literature Review}

According to Chong and Goh (2005), with regards to the effect of macroeconomic variables on stock prices, the Efficient Market Hypothesis (EMH) proposes that due to the competition among the profit-maximizing investors in an efficient market, it will make sure that all the available and relevant public information currently known about the changes in the macroeconomic variables are completely reflected in the current stock prices. Hence, investors will not be able to earn abnormal profit through the prediction of the future stock market movements.

There is a considerable member of studies that have been conducted on the impact of financial variables on stock prices. Besides, Aisyah et al. (2009) states that the macroeconomic variable such as interest rate influences the stock market returns. For example, restrictive policies via higher interest rates would make cash flows worthless after discounts. Thus, it would lower the attractiveness of the investment and shrink the value of the stock return. Research has been conducted by Fama (1981) in which he finds that stock prices are the reflectors of various macroeconomic variables such as interest rate, inflation rate, exchange rate and industrial production.

Henry (1986) analyses the effects of interest rates and other macroeconomic variables, along with dummy variables to capture the impact of the Asian Financial Crisis 1997. His findings confirm the effects of the macroeconomic variables such as interest rates towards the stock market indices in countries under study, though the magnitude of associations differed depending on the country's financial structure. Islam (2003) extended the above research to investigate the long-run equilibrium and the short-run dynamic adjustment relationship between macroeconomic variables (interest rate, inflation rate, exchange rate and industrial productivity) and the Kuala Lumpur Stock Exchange (KLSE) Composite Index. He 
finds that it is statistically proven that there are significant longrun (equilibrium) and short-run (dynamic) relationships among the interest rates and the KLSE stock returns. The research findings from Islam and Watanapalachaikul (2003) show a significant long-run relationship between interest rates and stock prices during the period 1992 to 2001 in Thailand.

The volatility of the stock market refers to the price variation of the stock market over time (Zvi, Alex \& Alan, 2009). The volatility and risk issues have become gradually important to market participants, financial practitioners, researchers and regulators. Campbell (1996) asserts that stock market volatility affects consumer spending. The impact is linked via wealth effect. He explains that when wealth increases, it will drive consumer-spending up. Nevertheless, consumer confidence falls when the stock market falls and drives consumer-spending down. The volatility of the stock market can be inferred as an increase of risk in equity investment and results in a shift of funds to a less risky asset. According to Zuliu (1995), stock market volatility also distresses business investment. His research investigates whether the volatility of the stock market influences the real fixed investment. His analysis indicates that the volatility of the stock market is negatively related to the growth of investment. In addition, the stock market volatility weakens fixed capital formation; hence, the outcomes recommend the desirability of reducing the volatility of the stock market.

Ehrhardt (1991) states that interest rates have powerful effects towards stock returns. Furthermore, Koh and Maysami (2000) investigate the impacts of interest rate on the stock returns and the result shows that the interest rate is one of the determinants in predicting the stock prices. Likewise, similar outcomes are achieved in various studies in different countries such as Alper (2007) and Gulin and Gokce (2008). By using wavelet analysis with the Granger causality test, Cifter and Ozun (2007) investigate the impact of interest rate volatility on stock returns in Turkey. They find that the effect of interest rate is granger causes ISE 100 index. Furthermore, the effects of the interest rates on stock returns increases with higher time scales. Bren et al. (1989) examine the significance of predictable variations in stock index returns. They find that the one-mouth interest rate is useful in predicting the sign and the variance of the excess returns on stocks.

Cheong (2008) investigates the fractionally integrated behaviour of KLSE's volatility from 2000 to 2005 and find that during the recovery period, the stock market exhibits the presence of risk premium, long- 
memory volatility, and significant relationship between news and volatility. This implies that bad news has higher predictive power for upcoming volatility and finally the existence of heavy-tailed property in selected volatility models. N'dri (2008) examines the influence of interest rates towards stock market returns and volatility by using weekly returns on the KOSPI 200 from 1992 to 1998. The results of this research found that the market returns of KOSPI 200 have a negative and significant relationship with interest rates. At the same time, the variance of returns has a positive but not significant relationship with interest rates. The findings indicate that the interest rates have a strong positive power for stock returns, however, a weak predictive power for volatility of KOSPI 200.

\section{Data and Methodology}

Stock market indices, such as the FBM KLCI and the STI index, are widely used for measuring the performance of the stock market. Interest rates refer to the cost of obtaining capital. In this research, it is proxied by the average of the interbank deposit rates in the Interbank Money Market. Generally, the central banks in the countries conduct the monetary policy by influencing the level of interest rate. The decision of injecting or withdrawing funds which is made by the central bank would influence the level of interest rate in the financial system. The monthly FBM KLCI and the 3 - months deposit yield data in Malaysia are used for the period beginning in September 1999 and ending in December 2010. For Singapore, the monthly STI and the 3-months deposit yield in Singapore for the same period are used in order to do the comparison. All the data were obtained from the Data Stream System.

The continuously compounded monthly index returns are calculated using the formula below, where $Y_{t}$ represents the return on the market index.

$$
Y_{t}=\log \left(P_{t} / P_{t-1}\right) \times 100
$$

$P_{t}$ represents the market index price at time $t$ and $P_{t-1}$ represents the index price at $t-1$. Interest rate is first differenced and then compounded continuously because the main purpose is to appreciate the effect of volatility in the interest rates on stock market returns and volatility. 
The AutoRegressive Conditional Heteroscedasticity (ARCH) model was introduced by Engle (1982) to estimate the conditional mean return and volatility models. The main idea of $\mathrm{ARCH}$ is that the variance of $u$ at time $t\left(=\sigma_{t}^{2}\right)$ depends on the size of the squared error term at time $(t-1)$, that is on $u_{t-1}^{2}$. Nevertheless, the ARCH model has a few difficulties as it is hard to decide the number of lags $(q)$ of the squared residual. The lags of squared error which are needed to capture all of the dependence in conditional variance might have large varying. Furthermore, the more parameters there are in the conditional variance equation, the more that one or more of them will have negative estimated values.

This model was further extended by Bollerslev (1986) into the Generalized Autoregressive Conditional Heteroscedasticity (GARCH) in which is commonly applied the class of time series models in recent financial literature in studying volatility. The difference between $\mathrm{ARCH}$ and GARCH is that the conditional variance of $u$ at time $t$ in the GARCH model is dependent not only on past squared disturbances but also on past conditional variances.

Researches on the relationship between the stock market and the return volatility method by using the multivariate GARCH model have been growing like mushrooms. For instance, the GARCH model is being widely applied in examining the volatility of the stock market in developed and emerging countries. The studies include Huang (1995) for nine Asian countries; Lee, Chen and Rui (2001) for China; Cheung and Coutts (2001) for Hong Kong; Karmakar (2003) for India; Lima and Tabak (2004) for Hong Kong and Singapore; N'dri (2008) for Korea, Ravinder,Himadri and Pramod (2009) for 10 emerging markets.

As it has been proven that the GARCH model is an effective tool for examining stock market volatility, it is employed in the methodology of this research.

The equation for GARCH $(p, q)$ can be represented as follows:

$$
\begin{aligned}
& Y_{t}=\gamma_{0}+\gamma_{1} Y_{t-i}+\varepsilon_{t} \\
& \sigma^{2}{ }_{t}=\alpha_{0}+\sum_{i=1}^{p} \alpha_{i} \varepsilon_{t-i}^{2}+\sum_{j=1}^{q} \beta_{j} \sigma^{2} t-j
\end{aligned}
$$

Where $Y_{t}$ represents the return on the index, $Y_{t-1}$ is the lagged return series, $\gamma_{0}$ is a constant term and $\varepsilon_{\mathrm{t}}$ represents the error term in the equation (2). $p$ is the order of the autoregressive GARCH terms and 
$q$ is the order of the moving average $\mathrm{ARCH}$. The variance of $\sigma^{2}{ }_{t}$ is a function of the mean $\alpha_{0}$, the long-term average volatility. The ARCH term notated by $\varepsilon_{t-i}^{2}$ is the interest rate volatility. The GARCH term notated by $\sigma_{t-j}^{2}$ is the previous period's forecast variance.

GARCH specification requires that parameters $\alpha_{0}, \alpha_{\mathrm{i}}$ and $\beta_{j}$ should be positive for non-negativity condition and the sum of $\alpha_{\mathrm{i}}$ and $\beta_{j}$ should be less than one to secure covariance stationarity of the conditional variance.

$$
\sum_{i=1}^{q} \alpha_{i}+\sum_{j=1}^{p} \beta_{j}<1
$$

The persistence degree in shocks to volatility is the total of the coefficients $\alpha_{\mathrm{i}}$ and $\beta_{j}$ that need to be less than or equal to unity for stability to hold.

The estimation of the GARCH model involves the joint estimation of a mean and a conditional variance equation. In order to appreciate the impacts of interest rate volatility on the monthly conditional index returns and variances, two models are employed. Model 1 is without the changes of interest rate, while model 2 is with the changes of interest rates in the mean and variance.

\section{Model 1:}

$$
\begin{aligned}
& Y_{t}=\gamma_{0}+\gamma_{1} Y_{t-1}+\varepsilon_{t} \\
& \sigma^{2}=\omega+\alpha \varepsilon_{t-1}^{2}+\beta \sigma^{2}=1
\end{aligned}
$$

Model 2:

$$
\begin{aligned}
& Y_{t}=\gamma_{0}+\gamma_{1} Y_{t-1}+\gamma_{2} R_{t}+\varepsilon_{t} \\
& \sigma^{2} t_{t}=\omega+\alpha \varepsilon_{t-1}^{2}+\beta \sigma_{t-1}^{2}+\lambda R_{t}
\end{aligned}
$$

Where $\gamma_{0}, \gamma_{1}, \omega, \alpha$ and $\beta$ are constant terms. $Y_{t}$ represents the return on the index, the change in the logarithm of the index price in period $t, \varepsilon_{t}$ is the disturbance term and $R_{t}$ is the variable reflecting interest rate changes or volatility.

\section{Findings}

The estimates of the conditional market variance equation parameters will be first discussed. Then, it will followed by the discussion of the estimates of the conditional mean equation. Table 1 shows the 
estimates of Model 1 and Model 2 for the FBM KLCI sample period. Model 1 indicates the estimates without interest rates while Model 2 includes interest rate volatility in both conditional mean and variance.

Table 1

Estimates of Model 1 and Model 2 for FBM KLCI

\begin{tabular}{ccc}
\hline & Model 1 & Model 2 \\
\hline$\gamma_{0}$ & 0.0052 & 0.0436 \\
& $(0.1680)$ & $(0.0683)$ \\
$\gamma_{1}$ & 0.1720 & 0.0643 \\
& $(0.0421)$ & $(0.4048)$ \\
$\gamma_{2}$ & --- & -0.0121 \\
& 0.0001 & $(0.1169)$ \\
$\omega$ & $(0.1863)$ & -0.0010 \\
$\alpha$ & 0.1385 & $(0.0000)$ \\
$\beta$ & $(0.0225)$ & -0.0513 \\
& 0.8200 & $(0.0025)$ \\
$\lambda$ & $(0.0000)$ & 1.0019 \\
Log-lik. & --- & $0.0000)$ \\
\hline
\end{tabular}

Notes. Log-lik. is the log-likelihood function. P-values which are significant at 5\% level are shown in parentheses.

The result from Table 1 indicates that the point estimates of conditional variance parameters for Model 1 and Model 2 are almost the same. The result shows that the conditional volatility of returns is fairly persistent for Model 1 and Model 2. The sum of $\alpha$ and $\beta$ is 0.9585 for Model 1 and 0.9506 for Model 2, in which both results are less than 1 . The results for Model 1 in Table 1 are very similar to the results reported by N'dri (2008). This indicates that volatility of return is mean; reverting no matter how much time it takes, the process of volatility does return to its mean.

Model 2 contains the interest rates in the conditional variance and mean equation. The estimate of $\lambda$ in variance equation (7) is positive and statistically significant. The result above suggests that interest rate contributes in predicting FBM KLCI's volatility. The result is consistent with the results indicated by Campbell (1987), Shanken (1990) and Whitelaw (1994). The result above shows that interest rates do help in predicting stock market volatility in Malaysia. 
In the conditional mean equation (6), the estimate of $\gamma_{2}$ is negative but not significant. The negative relationship between interest rates and conditional market return is consistent with the results reported by Giovannini et al. (1987), Campbell (1987) and Shanken (1990). This points to less significant predictive power of interest rates on the market returns in Malaysia.

Table 2

Estimates of Model 1 and Model 2 for STI

\begin{tabular}{ccc}
\hline & Model 1 & Model 2 \\
\hline$\gamma_{0}$ & 0.0073 & 0.0132 \\
$\gamma_{1}$ & $(0.1104)$ & $(0.0886)$ \\
& 0.1764 & 0.1332 \\
$\gamma_{2}$ & $(0.1193)$ & $(0.1833)$ \\
& --- & -0.0021 \\
$\omega$ & 0.0001 & $(0.7132)$ \\
$\alpha$ & $(0.0982)$ & -0.0003 \\
$\beta$ & 0.1380 & $(0.0000)$ \\
& $(0.0081)$ & 0.0661 \\
$\lambda$ & 0.8230 & $(0.0154)$ \\
Log-lik. & $(0.0000)$ & 0.9247 \\
& --- & $0.0000)$ \\
& 190.2621 & 0.0002 \\
& & $(0.0000)$ \\
\hline
\end{tabular}

Notes. Log-lik. is the log-likelihood function. P-values which are significant at 5\% level are shown in parentheses.

Table 2 shows the estimates of Model 1 and Model 2 for the STI sample period. It is similar to Table 5 in which Model 1 indicates the estimates without interest rates while Model 2 includes interest rate volatility in both the conditional mean and variance.

The results for STI are very similar to the result showed in the FBM KLCI. The result from Table 2 specifies that the point estimates of conditional variance parameters are almost the same for Model 1 and Model 2, with the sum of $\alpha$ and $\beta$ being 0.9610 and 0.9908 for Model 1 and Model 2 respectively. Both the sum of $\alpha$ and $\beta$ are less than 1 .

As mentioned, Model 2 includes the interest rates in the conditional variance and mean equation. The estimate of $\lambda$ in variance equation (7) is also positive and statistically significant at the $5 \%$ level. The 
above result indicates that historical interest rate volatility has a positive relationship with STI volatility. Additionally, the inclusion of interest rates in the conditional variance significantly affects the estimates of $\omega, \alpha$ and $\beta$ in the model as well. The result above shows that interest rates do help in predicting volatility in Singapore.

In the conditional mean equation (6), estimate of $\gamma_{2}$ is negative but not significant at the $5 \%$ level. The result is consistent with the result found in the FBM KLCI. This result shows that the predictive power of interest rates on stock market return in Singapore is not significant. The result is consistent with the result reported by Ramin et al. (2004).

The diagnostic check of standard residuals is carried out to check Model 1 and Model 2 for both markets. The results are shown in Table 3 and Table 4 below.

Table 3

Diagnostic Check for FBM KLCI

\begin{tabular}{ccccc}
\hline & \multicolumn{2}{c}{ Standardized residuals } & \multicolumn{2}{c}{ ARCH LM Test } \\
\cline { 2 - 5 } & Skewness & Kurtosis & F-statistic & Obs* R-squared \\
\hline \multirow{2}{*}{ Model 1 } & \multirow{2}{*}{-0.3445 } & \multirow{2}{*}{4.0967} & 0.0202 & 0.0205 \\
& & & $(0.8871)$ & $(0.8861)$ \\
\multirow{2}{*}{ Model 2 } & \multirow{2}{*}{-0.1967 } & \multirow{2}{*}{2.9207} & 0.0191 & 0.01936 \\
& & & $(0.8903)$ & $(0.8893)$ \\
\hline
\end{tabular}

Notes. P-values are in parentheses.

Table 4

Diagnostic Check for STI

\begin{tabular}{ccccc}
\hline & \multicolumn{2}{c}{ Standardized residuals } & \multicolumn{2}{c}{ ARCH LM Test } \\
\cline { 2 - 5 } & Skewness & Kurtosis & F-statistic & Obs $^{*}$ R-squared \\
\hline \multirow{2}{*}{ Model 1 } & \multirow{2}{*}{-0.5676 } & \multirow{2}{*}{3.7076} & 0.2480 & 0.2514 \\
& & & $(0.6193)$ & $(0.6161)$ \\
Model 2 & \multirow{2}{*}{-0.3451 } & \multirow{2}{*}{3.1829} & 2.2111 & 2.2076 \\
& & & $(0.1394)$ & $(0.1373)$ \\
\hline
\end{tabular}

Notes. P-values are in parentheses.

The ARCH Lagrange multiplier (LM) test is used to do the diagnostic check for the two models in both the Malaysia and Singapore markets. Table 3 shows the result of the diagnostic check for FBM KLCI, while 
Table 4 shows the result for STI. The kurtosis for FBM KLCI and STI are both peaked relative to the normal. Table 3 and Table 4 also show negative skewness which indicate that the standardized residuals are not normally distributed. The ARCH LM test statistics for the 2 models in both markets show that the standardized residuals do not exhibit additional ARCH effects. This indicates that the variance equations are well specified in the two models in both markets and the test confirms all the models are fairly specified.

\section{Conclusion}

This research paper examines the effect of interest rate volatility on the stock market returns and volatility in Malaysia and Singapore. Two GARCH $(1,1)$ models are applied in the analysis for the respective countries. Model 1 in the analysis is without interest rates, while Model 2 incorporates interest rates in the conditional mean and variance. The study period for this research started in September 1999 and ended in December 2010. Similar results are found for the both markets. The results for both models in the two markets show that the estimates of variance parameters and conditional market returns are nearly identical in which the sum of $\alpha$ and $\beta$ are less than one. Furthermore, the results for both markets suggest that historical interest rate volatility has a positive relationship with stock market volatility. In other words, the results show that interest rates in both Malaysia and Singapore do help in predicting the volatility in their own stock markets. The findings of predictive power of interest rates on stock market returns for both the FBM KLCI and STI are also similar. The result shows that the volatility of interest rates in each country has a negative relationship with the stock market returns of FBM KLCI and STI. However, the results are not statistically significant.

The results of this research have a substantial influence in policy implication for investors. As stated by N'dri (2008) interest rates affect the decision of investors to either invest the fund in bond or equity market. This research has shown that interest rates do affect the volatility of both markets. Investors should keep their eyes on the monetary policy as a means for adjusting their investments in Malaysia and Singapore. Since the result shows that the predictive power of interest rates on stock market returns for the FBM KLCI and STI are not significant, it suggests that there could be other macroeconomic 
factors that might affect the stock market returns in Malaysia and Singapore. The other macroeconomic factors are referring to inflation, exchange rates, industrial production and money supply in Malaysia and Singapore. Future research can further investigate the predictive power of the other macroeconomic factors on the stock market returns for both markets.

\section{References}

Aisyah, A. R., Noor, Z., \& Fauziah, H. T. (2009). Macroeconomic determinants of Malaysian stock market. African Journal of Business Management, 3(3), 95-106.

Alper, O. (2007). International transmission of volatility in the US interest rates into the stock returns: Some comparative evidence from world equity markets. International Research Journal of Finance and Economics, 10, 129-138.

Bollerslev, T. (1986). Generalized autoregressive conditional heteroskedasticity. Journal of Econometrics, 31(1), 307-327.

Campell, J. Y. (1987). Stock return and the term structure. Journal of Financial Economics, 18, 373-399.

Campell, J. Y. (1996). Consumption and the stock market: Interpreting international experience. NBER Working Paper, 5610.

Chen, M. H. (2003). Risk and return: CAPM and CCAPM. Review of Economy and Finance, 43, 369-393.

Chen, N. F. (1991). Financial investment opportunities and the macroeconomy. Journal of Finance, 46, 529-554.

Cheong, C. W. (2008). Volatility in Malaysian stock market: An empirical study using fractionally integrated approach. American Journal of Applied Sciences, 5(6), 683-688.

Chong, C. S., \& Goh K. L. (2005). Intertemporal linkages of economic activity, stock price and monetary policy in Malaysia. Asia Pacific Journal of Economics and Business, 9(1), 48-61.

Cheung, K-C., \& Coutts, J. A. (2001). A note on weak form market efficiency in security prices: Evidence from Hong Kong stock exchange. Applied Economic Letters, 8, 407-410.

Davis, E. P. (1990). An industrial approach to financial instability. Bank of England Discussion Papers no. 50, London.

Engle, R. F.(1982). Autoregressive conditional heteroscadasticity with estimates of the variance of the U. K inflation. Econometrica, 50(3), 987-1008.

Fama, E. F. (1970). Efficient capital market: A review of theory and empirical work. Journal of Finance, 25(2), 383-417. 
Fama, E. F. (1981). Stock returns, real activity, inflation and money. American Economic Review, 71, 545-565.

Fama, E. F. (1990). Stock returns, expected returns, and real activity. Journal of Finance, 45, 1089-1108.

Fama, E. F. (1991). Efficient capital markets: II. Journal of Finance, 46, 1575-1617.

Giovannini, A., \& Jorion, P. (1987). Interest rates and risk premia in the stock market and foreign exchange market. Journal of International Money and Finance, 6(1), 107-123.

Gulin, V., \& Gokce, A. (2008). Effects of interest and exchange rate on volatility and return of sector price indices at Istanbul stock exchange. European Journal of Economics. Finance and Administrative Sciences, 11, 127-134.

Hashemzadeh, N., \& Taylor, P. (1988). Stock prices, money supply and interest rate: The question of causality. Applied Economic, 20, 1603-1611.

Huang, B. N. (1995). Do Asian stock market prices follow random walks? Evidence from the variance ratio test. Applied Financial Economics, 5, 251-256.

Ibrahim, M. H. (2000). Co-integration and granger causality tests of stock price and exchange rate interactions in Malaysia. ASEAN Econ. Bulletin, 17(1), 36-47.

Ibrahim, M. H., \& Aziz, H. (2003). Macroeconomic variables and the Malaysian equity market: A view through rolling subsamples. Journals of Economic Study, 30(1), 6-27.

Islam, M. (2003). The Kuala Lumpur stock market and economic factors: A general to-specific error correction modeling test. Journal of the Academy of Business and Economics, 1(1),

Islam, S. M. N., \& Watanapalachaikul, S. (2003). Time series financial econometrics of the Thai stock market: A multivariate error correction and valuation model. Retrieved from http://blake.montclair.edu

Janor, H. (2005). Stock market and economic activity in Malaysia. Investment, Manage and Finance Innovation, 4, 116-123.

Karmakar, M. (2003). Heteroscedastic behaviour of the Indian stock market: Evidence and explanation. Journal of Academy of Business and Economics, 1, 27-36.

Kaneko, T., \& Lee, B. S. (1995). Relative importance of economic factors in the U.S. and Japanese stock markets. Journal of Japanese International Economy, 9, 290-307.

Kaufman, H. (1986). Interest rates, the markets and the new financial world. London: I. B. Tauris.

Lee, C. F., Chen, G. M., \& Rui, O. M. (2001). Stock returns and volatility on China's stock markets. The Journal of Financial Research, 24, 523-543. 
Levine, R., \& Zervos, S. (1996). Stock market development and longrun growth. World Bank Economic Review, 10(1), 323-339.

Lima, E. J. A., \& Tabak, B. M. (2004). Tests of the random walk hypothesis for equity markets: Evidence from China, Hong Kong and Singapore. Applied Economic Letter, 11, 255-258.

Maysami, R., \& Koh, T. S. (2000). A vector error correction model of Singapore stock market. International Review of Economy. 9, 79-96.

N'dri, K. L. (2008). The effects of interest rates volatility on stock returns and volatility: Evidence from Korea. International Research Journal of Finance and Economics, 14, 285-290.

Poterba, J. M. (2000). Stock market wealth and consumption. Journal of Economic Perspectives, 14(2), 99-118.

Ramin, C. M., \& Lee, C. H. (2004). Relationship between macroeconomic variables and stock market indices: Cointegration evidence from stock exchange of Singapore's all-S sector indices. Journal of Management, 24, 47-77.

Ramin, C. M., Lee, C. H., \& Mohamad, A. H. (2004). Relationship between macroeconomic variables and stock market indices: Cointegration evidence from stock exchange of Singapore's All-S sector indices. Journal of Management, 24, 47-77.

Ravinder, K. A., Himadri, D., \& Pramod, K. J. (2009). Stock return and volatility: Evidence from select emerging markets. Review of Pacific Basin Financial Market and Policies, 12, 567-592.

Shanken, J. (1990). Intertemporal asset pricing. Journal of Econometrics, 45, 99-120.

Whitelaw, R. F. (1994). Time variation and covariations in the expectation and volatility of stock market returns. Journal of Finance XLIX, 2, 515-541.

Zvi, B., Alex, K., \& Alan, J. M. (2009). Investment (8th ed.). Singapore: McGraw-Hill.

Zuliu, H. (1995). Stock market volatility and corporate investment. IMF Working Paper, 95/102. 